José Marçal Jackson Filho

Eduardo Garcia Garcia

Ildeberto Muniz de Almeida

\section{A Saúde do Trabalhador como problema público ou a ausência do Estado como projeto} \author{
as a policy \\ as a policy
} Workers' Health as a public problem or the absence of the state

Este número temático da Revista Brasileira de Saúde Ocupacional trata de assunto central para o campo da Saúde do Trabalhador: acidentes do trabalho e sua prevenção.

A prevalência de acidentes e doenças do trabalho é mais um indicador de desigualdade social e cultural e, portanto, de injustiça. Morre-se mais de causas associadas ao trabalho nas classes de trabalhadores assalariados do que nas de profissionais liberais, assim como são variadas as proporções de acidentes do trabalho nas diversas sociedades (WOODING, J.; LEVENSTEIN, C. The point of production. Work environment in advanced industrial societies. New York: The Guilford Press, 1999. p. 12-13). Por isso, pode-se dizer que a "saúde do trabalhador" é um problema público, no sentido proposto por John Dewey (The public and its problems. Athens: Swallow Press, 1991 [1927]), isto é, que exige ações mediadoras e reguladoras do Estado.

A manutenção de mecanismos de alocação de responsabilidade baseados na “culpabilização das vítimas”, descritos já há algum tempo pelas Ciências Sociais (DOUGLAS, M. Risk acceptability according to the social sciences. New York: Rusell Sage Foundation, 1985), certamente contribui de forma relevante para esse problema e, no caso do Brasil, aponta para a insuficiência da ação do Estado no campo da saúde do trabalhador atestada pelo grande número de acidentes de trabalho notificados. A despeito de todas as evidências da influência de fatores sistêmicos, a predominância do enfoque que culpabiliza as vítimas por seus "atos inseguros", muitas vezes, também é sustentada por agentes públicos, perpetuando-se, assim, a impunidade nos acidentes do trabalho e a injustiça social (VILELA, R. A. G.; IGUTI, A. M.; ALMEIDA I. M. Culpa da vítima: um modelo para perpetuar a impunidade nos acidentes do trabalho. Cad. Saúde Pública, Rio de Janeiro, v. 20, n. 2, p. 570-579, 2004).

Por meio desses mecanismos, dificulta-se questionar a responsabilidade das organizações e instituições públicas e se favorecem o controle e a coerção social (DOUGLAS, 1985). Tal quadro é agravado pelo "enfraquecimento e pouca capacidade de pressão dos movimentos sociais e dos trabalhadores" (GOMEZ, C. M.; LACAZ, F. A. C. Saúde do trabalhador: novas-velhas questões. Ciênc. saúde coletiva, Rio de Janeiro, v. 10, n. 4, p. 797-807, 2005. p. 797).

Embora esse modelo de análise de acidentes - baseado na dicotomia entre atos e condições inseguras - sirva de regra profissional, prevista até em norma brasileira (ABNT. NBR 14280. Cadastro de acidente do trabalho: procedimento e classificação, fev. 2001), ele se fundamenta em referencial teórico e metodológico limitado sob vários aspectos, sem considerar, por exemplo, achados atuais sobre a ação e a cognição humanas no trabalho (ASSUNÇÃO, A. A.; LIMA, F. P. A contribuição da Ergonomia para a identificação, redução e eliminação 
da nocividade do trabalho. In: MENDES, R. [Org.]. Patologia do trabalho. 2. ed. v. 2. São Paulo: Atheneu, 2005. p. 1767-1789).

Douglas (1985, p. 56), que considera o mecanismo de culpabilização da vítima um "meio de iludir" para se "lavar as mãos", ilustra: "quando o piloto morto pode ser culpado pelo erro que levou seu avião ao acidente, não há necessidade de se investigar profundamente a adequação do controle de tráfego aéreo ou o estado do avião”. Por analogia, refletindo sobre o acidente aéreo recente com o avião da GOL do vôo 1907, será que ao procurar restringir a responsabilidade a controladores aéreos e pilotos não se está tentando omitir questões relativas às más condições de trabalho, à pouca confiabilidade do sistema de controle, à alta carga de trabalho ou ao seu modo de organização?

Esse "método" para análise de acidentes é, de acordo com a idéia de Douglas (1985), um meio que permite aos atores sociais que determinam de fato as condições de execução do trabalho "se desresponsabilizar" pelas conseqüências dos acidentes. Protegem-se os empregadores e seus prepostos, ao mesmo tempo em que se encobre a insuficiente ação do Estado e das instituições públicas envolvidas. Se, de um lado, os acidentes resultam de construção social com tonalidades próprias à nossa cultura, a culpabilização da vítima como "método" de análise de acidentes hegemônico no Brasil é um impedimento para a construção técnica e social de ações e políticas efetivas de prevenção.

Diante da re-estruturação da economia e da produção, a situação tende a se agravar, como mostram as recentes pesquisas européias sobre condições de trabalho e saúde (PAOLI, P.; MERLIE, D. Troisième enquête européene sur les conditions de travail - 2000. Dublin: Fondation européenne pour l'amélioration des conditions de vie et de travail, 2001): o número de trabalhadores expostos a riscos tradicionais (levantamento e carregamento de cargas pesadas, substâncias tóxicas, ruído, calor, dentre outros) permaneceu no mesmo patamar enquanto aumentou o número de trabalhadores expostos a fatores de risco psicossociais (pressão da clientela e da produção, formas de intimidação e de controle). Novas formas de adoecimento estão associadas a processo evidente de intensificação do trabalho.

Por outro lado, com o avanço das políticas neoliberais, assiste-se ao enfraquecimento do Estado, que se fundamenta em "processo de subjetivação da desnecessidade do público" (OLIVEIRA, F. Privatização do público, destituição da fala e anulação da política: o totalitarismo neoliberal. In: OLIVEIRA, F.; PAOLI, M.C. [Orgs.]. Os sentidos da democracia, políticas do dissenso e hegemonia global. Petrópolis: Vozes, 1999. p. 55-81), e, conseqüentemente, à sua menor intervenção no campo da segurança e saúde dos trabalhadores, com a transferência das questões de SST para o "controle interno" das empresas, com um agravante: para este controle interno, estão sendo propostos novos sistemas de gestão da SST baseados no velho princípio de que acidentes resultam de desvios do comportamento e faz-se necessária a gestão do comportamento dos trabalhadores.

O Estado Brasileiro está se ausentando das questões que envolvem a relação entre saúde e trabalho? A ausência do Estado constituir-se-á como norma para os tempos vindouros?

Este número especial, ao tratar deste tema crucial, procurou ir além da abordagem tradicional, que tende a separar as disciplinas de cunho técnico dos construtos sociais e políticos na explicação e compreensão dos fenômenos associados ao "meio ambiente do trabalho", conforme evidenciado nos dizeres de Wooding e Levenstein (1999, p.12-13.): "a medicina ocupacional, a higiene industrial, a epidemiologia ocupacional - a economia - são ensinadas e praticadas sob a ficção de que as políticas e os construtos sociais são considerações separadas da, e periféricas à, ciência dura”.

Nesta coletânea, que agrupa trabalhos de pesquisadores e atores de diversas instituições públicas, procurou-se, explicitamente, enfrentar "a fragmentação e dispersão da produção científica na área” que têm prejudicado “a importante colaboração que a Aca- 
demia poderia oferecer para fundamentar as necessidades dos agentes políticos, movimentos sociais, gestores e profissionais de saúde” (GOMES \& LACAZ, 2005, p. 797).

Os leitores da RBSO estão convidados a participar deste espaço de discussão, cujo objeto envolve temas ligados ao "problema público" da segurança e da saúde dos trabalhadores. 